\section{Risk factors for cardiovascular disease among the homeless and in the general population of the city of Porto, Portugal}

\author{
Fatores de risco cardiovascular em pessoas sem- \\ abrigo e na população geral da cidade do Porto, \\ Portugal
}

\author{
${ }^{1}$ Escola Superior de \\ Enfermagem, Universidade \\ do Minho, Braga, Portugal. \\ 2 Instituto de Saúde Pública, \\ Universidade do Porto, Porto, \\ Portugal. \\ ${ }^{3}$ Faculdade de Medicina \\ Dentária, Porto, Portugal. \\ ${ }^{4}$ Faculdade de Medicina, \\ Universidade do Porto, Porto, \\ Portugal. \\ Correspondence \\ L. P. Oliveira \\ Escola Superior de \\ Enfermagem, Universidade \\ do Minho. \\ Largo do Paço 4704-553, \\ Braga, Portugal. \\ laoliveira@ese.uminho.pt
}

\section{Abstract}

We described the distribution of risk factors for cardiovascular disease among homeless people living in the city of Porto, Portugal. Comparisons were made between subsamples of homeless people recruited in different settings and between the overall homeless sample group and a sample of the general population. All "houseless" individuals attending one of two homeless hostels or two institutions providing meal programs on specific days were invited to participate and were matched with subjects from the general population. We estimated sex, age and educationadjusted prevalence ratios or mean differences. The prevalence of previous illicit drug consumption and imprisonment was almost twice as high among the homeless from institutions providing meal programs. This group also showed lower mean systolic and diastolic blood pressure. Prevalence of smoking was almost 50\% higher in the overall homeless group. Mean body mass index and waist circumference were also lower in the homeless group and its members were almost five times less likely to report dyslipidemia. Our findings contribute to defining priorities for interventions directed at this segment of society and to reducing inequalities in this extremely underprivileged population.

Homeless Persons; Hypertension; Overweight; Obesity
Luis de Pinho Oliveira 1,2

Maria Lurdes Pereira 3

Ana Azevedo 2,4

Nuno Lunet 2

\section{Introduction}

Homelessness is an essentially urban phenomenon linked to social discrimination affecting millions of people worldwide 1 . Closely associated with individual factors (e.g. long term unemployment, family breakdown, mental illness, substance abuse) and societal factors (e.g. poverty, high housing costs, unfavorable labor market conditions), there has been an increasing tendency in homelessness in recent years, due to the economic and social crises that have affected many countries 2,3,4,5,6,7,8.

This social condition is also an important determinant of health and has been associated with an increased risk of physical and mental disease $9,10,11$. In comparison with the general population, mortality rates are reported to be higher among the homeless and premature death is more common 9,10,11, especially due to cardiovascular disease 11,12. In addition to a high prevalence of diabetes and hypercholesterolemia, the increased risk of cardiovascular disease has been attributed essentially to a high prevalence of hypertension and substance abuse 12,13,14,15,16. Several studies reported prevalence of hypertension among the homeless ranging from $14 \%$ to $51 \% 14,15,17,18,19,20,21$, and prevalence of tobacco and alcohol consumption of almost $80 \%$ and $30 \%$ respectively $12,14,22$. Furthermore, the fact that the homeless population experiences difficulties in obtaining and maintaining stable sources of medical care has also been described as a barrier to appropri- 
ate healthcare $23,24,25$ that contributes to a lack of awareness of these health problems and difficulties in adhering to treatment regimens 26 . In Portugal, however, these factors are expected to have a lower impact on the health status of the homeless population because healthcare assistance is provided by the National Health Service which is universal, comprehensive and free of charge for individuals that do not have the financial means to support the relatively low fees 27 .

Epidemiological research that targets such "hard-to-reach" populations also faces important methodological challenges, both due to the variety of operational definitions of homelessness and to the difficulties in sampling a numerically small and widely dispersed population living in anonymity 2,28,29,30. To ensure a valid comparison of results obtained in different settings and define strategies for monitoring risk factors for cardiovascular disease among the homeless, it is necessary to understand the impact of different sampling techniques on estimates.

To assess the effect of different recruitment settings on the estimate of the distribution of risk factors for cardiovascular disease, we evaluated two samples of homeless people: one assembled from homeless hostels and the other from institutions that run meals programs. We, then, compared these samples with the general population to quantify the association between homelessness and these determinants of health.

\section{Methods}

The present study comprises samples of homeless subjects and subjects from the general population living in the city of Porto, Portugal.

\section{Homeless subjects living in Porto}

\section{- Selection of study participants}

Between February and September 2009 we conducted a cross-sectional evaluation of homeless adults in the city of Porto. Participants were selected from individuals attending institutions that provide social services to the homeless (e.g. food, clothes and accommodation). Initially we contacted three of the most well-known organizations of this type in Porto, and asked the people responsible for running these services to identify similar homeless meeting venues in the city. Eleven local institutions were listed and invited to collaborate, of which three agreed to participate: one that provides accommodation to homeless people and administers two homeless hostels, and two institutions that manage meals programs (Figure 1). The other invited institutions did not reply in due time for their participation in the study.

For the present analysis we considered only individuals classified as "houseless" according to the European Federation of Organizations Working with the People who are Homeless (FEANTSA) 2: people who live in a place, but are excluded from the legal rights of occupancy and do not have conditions to enjoy normal social relations. "Roofless" people, those without a shelter of any kind, sleeping rough, were also identified under this recruitment strategy. Since only eight individuals were identified in this category, these subjects were excluded from data analysis. All participants had to be aged 18 years and over and be able to speak and understand Portuguese.

Considering that it would have been possible to select twice as many participants from homeless hostels than from institutions providing meals programs, and assuming a significance level of 5\% and $80 \%$ power, to assure an effective comparison between meals programs and homeless hostels, a minimum sample size of 44 participants selected from institutions providing meals programs and 88 selected from homeless hostels would be necessary to estimate prevalence ratios (PR) of 0.5 (prevalence $\geq 50 \%$ among subjects from homeless hostels) or 2 (prevalence $\geq 25 \%$ among subjects from homeless hostels).

We used a venue-based method for sampling 31,32 , with a systematic selection of the subjects attending each recruitment setting. Eligible subjects were invited to participate after being listed by the people responsible for running each setting based on institution's registration files. The invited individuals were asked to show up for evaluation on a predetermined day of the week. If an individual did not show upon the agreed day, a new day was scheduled. Three unsuccessful attempts were considered a refusal. Evaluations were conducted in the afternoon and evening in the homeless hostels, and after lunch time and in the evening in the institutions providing meals programs. Forty-two subjects refused to participate: 25 (21.6\%) of those invited from the homeless hostels and 16 (45.7\%) of those invited from one of the institutions providing meals programs and only one of those approached in the other institution providing meals programs, as depicted in Figure 1.

A face-to-face interview, with a structured questionnaire, and a physical examination were conducted in a total of 146 homeless subjects. Overall, no statistically significant differences were observed between participants and non-participants regarding sex (women: $13.7 \%$ vs. $21.4 \%$; $\mathrm{p}=0.222$ ), age (median: 45 vs. 47 years; $\mathrm{p}=0.301$ ) and education (median: 4.0 vs. 4.5 years; $\mathrm{p}=0.414$ ). However, the proportion of refusals was higher 
Selection of homeless and general population participants.

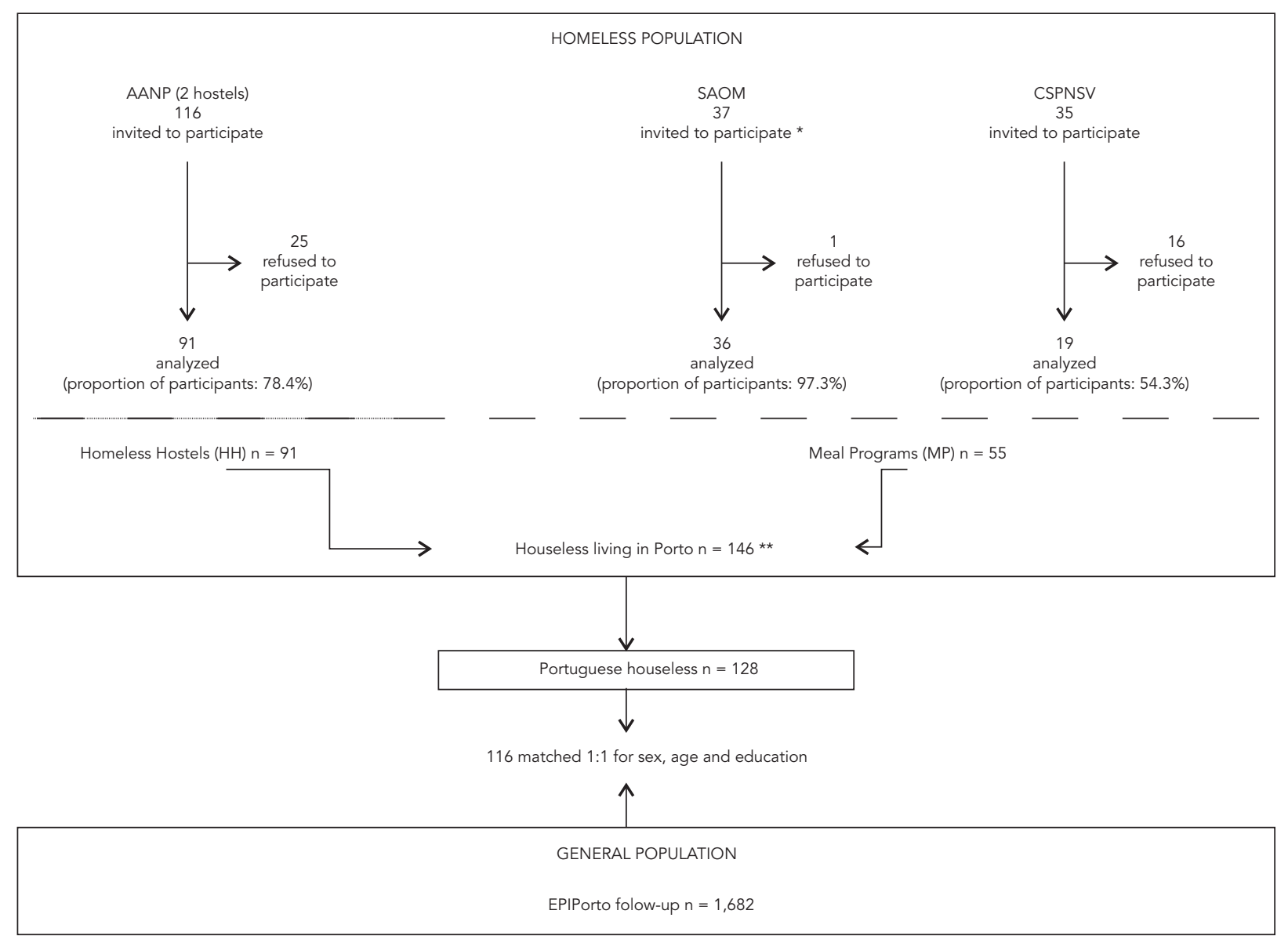

AANP: Associação dos Albergues Nocturnos do Porto; CSPNSV: Centro Social e Paroquial Nossa Senhora da Vitória; FEANTSA: European Federation of Organizations Working with Homeless People; SAOM: Serviço de Assistência Organizações de Maria.

* Only the subjects that were attending a hotel management course were approached;

** Houseless (according to the FEANTSA definition) - people who live in a place, but are excluded from the legal rights of occupancy and do not have conditions to enjoy normal social relations. This includes subjects living in homeless hostels (accessed directly or by referral from agencies; period of stay less than six months), in temporary accommodation (planned access or by referral from agencies; period of stay less than six months - e.g. low budget hotels, bed and breakfast, pensions or similar housing paid for by social services or Non-Governmental Organizations) or in transitional supported accommodation (planned access; longer term period of stay; supported accommodation for rehabilitation and re-settlement - e.g. rooms or houses paid by social services).

among women in the homeless hostels $(12.1 \%$ vs. $32 \% ; \mathrm{p}=0.017)$.

Each evaluation lasted around 45 minutes and was performed by trained staff from the research team in a private room located in the place where the subject was recruited.

\section{- Questionnaire}

A questionnaire designed to characterize the homelessness status of each participant and gather data on sociodemographic and behavioral characteristics (including tobacco and alcohol consumption), medical history (including previous diagnoses of hypertension, diabetes and dyslipidemia and medication use) and healthcare access/utilization was administered. 


\section{- Blood pressure and anthropometric evaluation}

Blood pressure was measured twice on a single occasion, using a digital blood pressure monitor (Omron HEM 7000-E; Omron Healthcare Inc., Lake Forest, USA), with an interval of 5 minutes between measurements, after a 10-minute rest, following the recommendations of the American Heart Association ${ }^{33}$.The mean of the two measurements was considered, and when the difference was larger than $5 \mathrm{mmHg}$ for systolic or diastolic blood pressure a third measurement was taken and the mean of the 2 closest values was registered.

Anthropometric measurements were obtained with the participant wearing light clothing and no footwear or head gear. Weight was measured with the subject in an upright position to the nearest $0.1 \mathrm{~kg}$ using a portable electronic weighing scale. Height was measured to the nearest $0.1 \mathrm{~cm}$ in the standing position using a portable stadiometer. Waist circumference was measured to the nearest $0.1 \mathrm{~cm}$, directly over the skin, or over light clothing, with a flexible and non-stretchable tape, avoiding exertion of pressure on the tissues and with the subject standing, at the level of the midpoint between the inferior margin of the last rib and the crest of the ileum in the midaxillary line at the end of a gentle expiration.

\section{General population living in Porto}

\section{- Selection of the study participants}

Non-homeless Porto residents selected for comparison with the homeless sample were participants in the EPIPorto cohort. Recruitment of the initial sample has been previously reported 34,35 . In brief, the cohort was assembled between 1999 and 2003 and comprised the evaluation of 2,485 Portuguese selected using random digit dialing among individuals and using the household as the basic sampling unit. The participation rate was $70 \% 35$. Follow-up took place between May 2005 and May 2008 at the Porto Medical School, with 1,682 members of the cohort. A subsample was selected from the latter group, matched (1:1) with the Portuguese homeless sample from Porto (Figure 1).

Assuming a significance level of $5 \%$ and a power of $80 \%$, in order to effectively compare the homeless sample with the general population sample, a minimum sample size of 121 homeless and 121 Porto residents would be needed to estimate a PR of 0.5 (prevalence $\geq 30 \%$ for the general population) or 2 (prevalence $\geq 15 \%$ for the general population).

Ninety-nine individuals were matched for sex, age ( \pm 5 years) and education level ( \pm 1 year), 12 individuals for sex, age ( \pm 5 years) and education level ( \pm 3 years), and five for sex, age ( \pm 10 years) and education level ( \pm 3 years). When more than one subject from the general population sample met the criteria for matching with a subject from the homeless sample, we selected the subject with the most similar education level (number of complete years of education). If more than one subject of the general population had a similar education level, we selected the one with the most similar age. If the criteria were met by more than one subject of the general population sample we opted for the one that had undergone the most recent follow-up evaluation. A match could not be found for 12 homeless, most of them young and with low education levels.

\section{- Questionnaire}

Trained interviewers conducted an extensive faceto-face evaluation that gathered data similar to the obtained from the homeless sample.

\section{- Blood pressure and anthropometric evaluation}

Blood pressure was measured twice on a single occasion by non-physician trained interviewers, using a mercury sphygmomanometer, using phase I and V Korotkoff sounds as the indicator for systolic and diastolic blood pressure, respectively, and following the recommendations of the American Heart Association 33, as previously described for the homeless.

Anthropometric measurements were obtained after an overnight fast, as previously described for the homeless.

\section{Statistical analysis}

Arterial hypertension was defined as systolic blood pressure $\geq 140 \mathrm{mmHg}$ and/or diastolic blood pressure $\geq 90 \mathrm{mmHg}$ and/or antihypertensive drug therapy 36 .

Body mass index (BMI) was calculated as weight in kilograms divided by the square of the height in meters and subjects were categorized in the following manner: underweight $\left(<18.5 \mathrm{~kg} / \mathrm{m}^{2}\right)$, normal $\left(18.5-24.9 \mathrm{~kg} / \mathrm{m}^{2}\right)$, overweight $(25.0-29.9 \mathrm{~kg} /$ $\left.\mathrm{m}^{2}\right)$ and obese $\left(\geq 30 \mathrm{~kg} / \mathrm{m}^{2}\right) 37$. Abdominal obesity was defined as a waist circumference greater than $102 \mathrm{~cm}$ in men or $88 \mathrm{~cm}$ in women 38 .

Regarding alcohol, participants were classified according to their consumption history as a "nondrinker", "ex-drinker" (for more than six months) and "current drinker". We assessed the frequency and level of consumption of each main type of alcoholic beverage (wine, beer, spirits or liquors). 
The daily intake of ethanol (g/day) was estimated by multiplying the quantity and frequency of each intake drink type by the corresponding average alcohol concentration ( $12 \%$ for wine, $4.7 \%$ for beer, $50 \%$ for spirits and $25 \%$ for liquors and similar beverages) 39. Following the recommendations of the American Heart Association 40, we defined high levels of alcohol consumption as a maximum daily intake of $15 \mathrm{~g} /$ day for women and $30 \mathrm{~g} /$ day for men. Regarding smoking habits, subjects were classified according to their history of tobacco consumption as a "non-smoker", "ex-smoker" (for more than six months) and "current smoker" (at least one cigarette per day at the time of the survey). The number of cigarettes consumed per day was also assessed.

We compared the distribution of the risk factors for cardiovascular disease between the homeless selected from homeless hostels and from institutions providing meals programs, and between the overall homeless sample and the general population sample, using adjusted PR and 95\% confidence intervals (95\%CI), computed using Poisson regression 41 , or adjusted $\beta$ coefficients with $95 \% C I$, computed using linear regression, for categorical and continuous variables, respectively.

Data was analyzed using Stata version 11.2 (Stata Corp., College Station, USA).

\section{Ethics}

These investigations were approved by the Ethics Committee of the Hospital de São João, Porto, and all participants gave written informed consent.

\section{Results}

Of the 146 homeless subjects enrolled in the study, approximately three-quarters were recruited in homeless hostels $(n=91)$. Overall average age was 45 years (range: 18 to 77 years) and less than $10 \%$ were aged over 60 years. Most of the subjects were men $(86.3 \%)$ and did not have a partner $(55.5 \%$ single, $27.4 \%$ divorced or separated and $4.1 \%$ widowed). A total of $88.3 \%$ reported having not reached tenth grade and the majority was unemployed $(78.8 \%)$ or retired (17.8\%). Non-Portuguese individuals $(\mathrm{n}=18)$ were mostly from eastern $\mathrm{Eu}$ ropean countries $(2.1 \%)$ and Portuguese ex-colonies $(9.6 \%)$. The median duration of homeless was 24 months (range: 1 to 480 months). Approximately one-quarter of the participants had used illicit drugs during the previous year, $21.2 \%$ had ever been imprisoned before and two stated that they had prostituted themselves before. Approximately ten percent reported having HIV/AIDS.

There was no statistically significant difference between the two sub-samples of homeless people regarding sociodemographic characteristics. However, the proportion of non-Portuguese individuals and subjects with less than four years of education was higher in the homeless hostels. Regarding homelessness status and behavioral characteristics, prevalence of previous consumption of illicit drugs and imprisonment was twice as high in the sample taken from institutions providing meals programs ( $18.7 \%$ vs. $32.7 \%$; $\mathrm{p}=0.054$ and $16.5 \%$ vs. $29.1 \% ; \mathrm{p}=0.071$ respectively) (Table 1 ).

Comparing institutions providing meals programs with homeless hostels, there was no significant difference regarding most risk factors for cardiovascular disease. There was however evidence of lower mean systolic ( $\beta=-10.37$; 95\%CI: -17.02 ; -3.72) and diastolic ( $\beta=-6.82$; 95\%CI: $-10.85 ;-2.78)$ blood pressures and lower prevalence of hypertension ( $\mathrm{PR}=0.53$; 95\%CI: $0.27 ; 1.04)$ among the sample from institutions providing meals programs. However, these differences did not reach statistical significance (Table 2). The magnitude of these associations remained essentially unchanged after further adjustment for body mass index (hypertension, PR = 0.52; 95\%CI: 0.26; 1.04; mean systolic blood pressure, $\beta=-9.64 ; 95 \% \mathrm{CI}$ : -16.36; -2.92; diastolic blood pressure, $\beta=-6.38$; 95\%CI: -10.46 ; -2.31 ). Among smokers, the average number of cigarettes consumed per day was similar between the two subsamples (16.5 vs. 16.6; $\beta=-0.19$; 95\%CI: -4.09 ; 3.71), in contrast to average daily alcohol intake, which was higher among subjects from the homeless hostels sample (53.4 vs.78.8; $\beta=-25.38 ; 95 \%$ CI: $-71.39 ; 20.62)$. There was no statistically significant difference between the two subsamples regarding average body mass index (24.7 vs. $25.5 \mathrm{~kg} / \mathrm{m}^{2} ; \beta=-0.87 ; 95 \% \mathrm{CI}:-2.64$; 0.91 ) and waist circumference ( 88.6 vs. $88.7 \mathrm{~cm} ; \beta=$ -0.08; 95\%CI: -4.16; 4.32).

Table 3 depicts the comparison between the overall homeless sample and the general population regarding exposure to risk factors for cardiovascular disease.

The prevalence of current smoking was almost $50 \%$ higher among the homeless group; however, the average daily consumption of cigarettes among smokers was lower in the homeless group compared to the general population (16.3 vs. 20.0 cigarettes/day; $\beta=-3.59 ; 95 \% \mathrm{CI}$ : $-7.61 ; 0.43)$. In contrast, although the proportion of current drinkers was slightly lower among the homeless, this group presented an approximately $10 \mathrm{~g}$ higher average daily consumption of alcohol (61.3 vs. 47.9g/day; $\beta=11.44$; 95\%CI: -7.57; 30.45).

The homeless individuals presented lower mean BMI (24.8 vs. $26.6 \mathrm{~kg} / \mathrm{m}^{2}, \beta=-1.64 ; 95 \% \mathrm{CI}$ : $-2.82 ;-0.46)$ and waist circumference (88.1 vs. 93.2cm; $\beta=-4.18$; 95\%CI: $-7.16 ;-1.21)$ and lower prevalence of overweight $(\mathrm{PR}=0.63$; 95\%CI: 0.40 ; 
Sample characteristics of the homeless, according to the recruitment setting.

\begin{tabular}{|c|c|c|c|c|}
\hline Socio-demographic characteristics & $\begin{array}{c}\text { All homeless } \\
\text { n (\%) * }\end{array}$ & $\begin{array}{l}\text { Meals programs } \\
n(\%) *\end{array}$ & $\begin{array}{l}\text { Homeless hostels } \\
\text { n (\%) * }\end{array}$ & $\mathrm{p}$-value \\
\hline \multicolumn{5}{|l|}{ Sex } \\
\hline Women & $20(13.7)$ & $9(16.4)$ & $11(12.1)$ & \\
\hline Men & $126(86.3)$ & $46(83.6)$ & $80(87.9)$ & 0.467 \\
\hline \multicolumn{5}{|l|}{ Age (years) } \\
\hline 18-39 & $45(30.8)$ & $15(27.3)$ & $30(33.0)$ & 0.607 \\
\hline $40-49$ & $47(32.2)$ & $21(38.2)$ & $26(28.6)$ & \\
\hline $50-59$ & $40(27.4)$ & $15(27.3)$ & $25(27.5)$ & \\
\hline$>60$ & $14(9.6)$ & $4(7.3)$ & $10(11.0)$ & \\
\hline \multicolumn{5}{|l|}{ Civil status } \\
\hline Married or civil union & $19(13.0)$ & $9(16.4)$ & $10(11.0)$ & 0.745 \\
\hline Single & $81(55.5)$ & $28(50.9)$ & $53(58.2)$ & \\
\hline Divorced or separated & $40(27.4)$ & $16(29.1)$ & $24(26.4)$ & \\
\hline Widowed & $6(4.1)$ & $2(3.6)$ & $4(4.4)$ & \\
\hline \multicolumn{5}{|l|}{ Education (years) } \\
\hline None & $4(2.7)$ & $1(1.8)$ & $3(3.3)$ & 0.094 \\
\hline $1-4$ & $70(48.0)$ & $21(38.2)$ & 49 (53.9) & \\
\hline $5-9$ & $55(37.7)$ & $28(50.9)$ & $27(29.7)$ & \\
\hline $10-12$ & $14(9.6)$ & $5(9.1)$ & $9(9.9)$ & \\
\hline$>12$ & $3(2.1)$ & $0(0.0)$ & $3(3.3)$ & \\
\hline \multicolumn{5}{|l|}{ Occupational status } \\
\hline Employed ** & $5(3.4)$ & $2(3.6)$ & $3(3.3)$ & 0.989 \\
\hline Unemployed & $115(78.8)$ & $43(78.2)$ & $72(79.1)$ & \\
\hline Retired & $26(17.8)$ & $10(18.2)$ & $16(17.6)$ & \\
\hline Nationality (\% Portuguese) & $128(87.7)$ & $52(94.6)$ & $76(83.5)$ & 0.050 \\
\hline \multicolumn{5}{|l|}{ Length of time spent homeless } \\
\hline$\leq 1$ month & $14(9.7)$ & $5(9.1)$ & $9(10.0)$ & 0.384 \\
\hline $2-6$ months & $32(22.1)$ & $12(21.8)$ & $20(22.2)$ & \\
\hline $7-12$ months & $17(11.7)$ & $3(5.5)$ & $14(15.6)$ & \\
\hline $1-5$ years & $43(29.7)$ & $17(30.9)$ & $26(28.9)$ & \\
\hline$\geq 6$ years & $39(26.9)$ & $18(32.7)$ & $21(23.3)$ & \\
\hline Use of illicit drugs (previous year) & $35(24.0)$ & $18(32.7)$ & $17(18.7)$ & 0.054 \\
\hline $\begin{array}{l}\text { Self reported HIV/AIDS (infection/ } \\
\text { disease) }\end{array}$ & $15(10.6)$ & $8(14.8)$ & $7(8.0)$ & 0.197 \\
\hline Practice of prostitution (ever) & $2(1.4)$ & $1(1.8)$ & $1(1.1)$ & 0.717 \\
\hline Imprisonment (ever) & $31(21.2)$ & $16(29.1)$ & $15(16.5)$ & 0.071 \\
\hline
\end{tabular}

* Results are presented as $n(\%)$, except when otherwise specified, and the percentages may not add up to $100 \%$ due to rounding;

** Pressman, kitchen assistant, solidarity institution server, barber or dustman.

$0.98)$ and obesity ( $\mathrm{PR}=0.47 ; 95 \% \mathrm{CI}: 0.24 ; 0.92)$ in comparison to the general population.

The differences observed between the homeless sample and general population regarding hypertension were not statistically significant. Additional adjustment for body mass index further attenuated the differences in the prevalence of hypertension ( $\mathrm{PR}=1.00 ; 95 \% \mathrm{CI}: 0.65 ; 1.55)$ and no meaningful difference was observed in the mean systolic ( $\beta=2.01 ; 95 \% \mathrm{CI}:-2.94 ; 6.96$ ) and diastolic blood pressure $(\beta=-1.07 ; 95 \% \mathrm{CI}$ : -4.59; 2.46).

The homeless were almost five times less likely to report dyslipidemia $(\mathrm{PR}=0.21 ; 95 \% \mathrm{CI}$ : $0.10 ; 0.43)$. 
Risk factors for cardiovascular disease among the homeless, according to the recruitment setting.

\begin{tabular}{|c|c|c|c|}
\hline & n (\%) & Crude PR $(95 \% \mathrm{Cl})$ & Adjusted* PR $(95 \% \mathrm{Cl})$ \\
\hline \multicolumn{4}{|l|}{ Cardiovascular risk factors } \\
\hline \multicolumn{4}{|l|}{ Current smoking } \\
\hline Homeless hostels & $68(58.6)$ & 1.00 (reference) & 1.00 (reference) \\
\hline Meals programs & $48(87.3)$ & $1.17(0.81 ; 1.69)$ & $1.16(0.81 ; 1.69)$ \\
\hline \multicolumn{4}{|c|}{ Current alcohol consumption } \\
\hline Homeless hostels & $70(76.9)$ & 1.00 (reference) & 1.00 (reference) \\
\hline Meals programs & $36(65.4)$ & $0.85(0.57 ; 1.27)$ & $0.86(0.57 ; 1.28)$ \\
\hline \multicolumn{4}{|c|}{ High level of alcohol consumption ** } \\
\hline Homeless hostels & $48(52.8)$ & 1.00 (reference) & 1.00 (reference) \\
\hline Meals programs & $22(40.0)$ & $0.76(0.46 ; 1.26)$ & $0.76(0.46 ; 1.26)$ \\
\hline \multicolumn{4}{|l|}{ 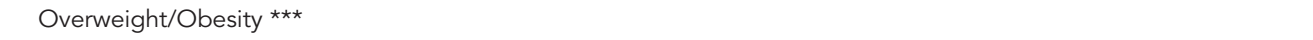 } \\
\hline Homeless hostels & $43(47.2)$ & 1.00 (reference) & 1.00 (reference) \\
\hline Meals programs & $18(32.7)$ & $0.69(0.40 ; 1.20)$ & $0.70(0.40 ; 1.20)$ \\
\hline \multicolumn{4}{|l|}{ Abdominal obesity \# } \\
\hline Homeless hostels & $19(19.1)$ & 1.00 (reference) & 1.00 (reference) \\
\hline Meals programs & $6(11.3)$ & $0.59(0.23 ; 1.50)$ & $0.60(0.24 ; 1.53)$ \\
\hline \multicolumn{4}{|l|}{ Hypertension } \\
\hline Homeless hostels & $35(38.5)$ & 1.00 (reference) & 1.00 (reference) \\
\hline Meals programs & $11(20.0)$ & $0.52(0.26 ; 1.02)$ & $0.53(0.27 ; 1.04)$ \\
\hline \multicolumn{4}{|c|}{ Self-reported health status/Healthcare use } \\
\hline \multicolumn{4}{|c|}{ Hypertension } \\
\hline Homeless hostels & $9(9.9)$ & 1.00 (reference) & 1.00 (reference) \\
\hline Meals programs & $5(9.1)$ & $0.92(0.31 ; 2.74)$ & $0.90(0.30 ; 2.69)$ \\
\hline \multicolumn{4}{|l|}{ Dyslipidemia } \\
\hline Homeless hostels & $8(9.1)$ & 1.00 (reference) & 1.00 (reference) \\
\hline Meals programs & $5(9.1)$ & $1.00(0.33 ; 3.06)$ & $1.02(0.33 ; 3.13)$ \\
\hline \multicolumn{4}{|l|}{ Diabetes } \\
\hline Homeless hostels & $8(9.1)$ & 1.00 (reference) & 1.00 (reference) \\
\hline Meals programs & $3(5.4)$ & $0.60(0.16 ; 2.26)$ & $0.56(0.15 ; 2.16)$ \\
\hline \multicolumn{4}{|c|}{ Evaluation of blood pressure (previous year) } \\
\hline Homeless hostels & $55(60.4)$ & 1.00 (reference) & 1.00 (reference) \\
\hline Meals programs & $36(65.5)$ & $1.08(0.71 ; 1.65)$ & $1.09(0.72 ; 1.66)$ \\
\hline \multicolumn{4}{|c|}{ Blood biochemical analyses (previous year) } \\
\hline Homeless hostels & $57(64.8)$ & 1.00 (reference) & 1.00 (reference) \\
\hline Meals programs & $49(89.1)$ & $1.38(0.94 ; 2.01)$ & $1.38(0.94 ; 2.02)$ \\
\hline
\end{tabular}

PR: prevalence ratio; $95 \% \mathrm{Cl}$ : $95 \%$ confidence interval.

* Adjusted for age (continuous) and education (continuous);

** High alcohol consumption defined according to the recommendations of the American Heart Association as a maximum daily intake of $15 \mathrm{~g} /$ day for women and $30 \mathrm{~g} /$ day for men;

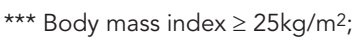

\# Abdominal obesity - waist circumference $\geq 102 \mathrm{~cm}$ (men) or $\geq 88 \mathrm{~cm}$ (women).

\section{Discussion}

Overall, apart from a lower prevalence of blood pressure observed in the sample selected from institutions providing meals programs, the present study showed few differences in the distribution of risk factors for cardiovascular disease according to the place of recruitment among the homeless subgroups. Obesity was less common and prevalence of smoking was higher in the overall homeless 
Risk factors for cardiovascular disease in Portuguese homeless subjects and general population living in Porto.

\begin{tabular}{|c|c|c|c|}
\hline & n (\%) & Crude PR $(95 \% \mathrm{Cl})$ & Adjusted * PR $(95 \% \mathrm{Cl})$ \\
\hline \multicolumn{4}{|l|}{ Cardiovascular risk factors } \\
\hline \multicolumn{4}{|l|}{ Current smoking } \\
\hline General population & $49(42.2)$ & 1.00 (reference) & 1.00 (reference) \\
\hline Homeless & $96(82.8)$ & $1.96(1.39 ; 2.76)$ & $1.91(1.35 ; 2.70)$ \\
\hline \multicolumn{4}{|c|}{ Current alcohol consumption } \\
\hline General population & $104(89.7)$ & 1.00 (reference) & 1.00 (reference) \\
\hline Homeless & $88(75.9)$ & $0.90(0.68 ; 1.20)$ & $0.91(0.69 ; 1.22)$ \\
\hline \multicolumn{4}{|c|}{ High level of alcohol consumption ** } \\
\hline General population & $68(58.6)$ & 1.00 (reference) & 1.00 (reference) \\
\hline Homeless & $57(49.1)$ & $0.85(0.64 ; 1.12)$ & $0.85(0.64 ; 1.14)$ \\
\hline \multicolumn{4}{|l|}{ 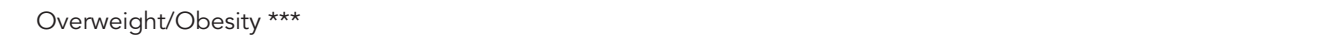 } \\
\hline General population & $73(62.9)$ & 1.00 (reference) & 1.00 (reference) \\
\hline Homeless & $47(40.5)$ & $0.64(0.45 ; 0.93)$ & $0.66(0.45 ; 0.95)$ \\
\hline \multicolumn{4}{|l|}{ Abdominal obesity \# } \\
\hline General population & $26(22.6)$ & 1.00 (reference) & 1.00 (reference) \\
\hline Homeless & $16(14.3)$ & $0.63(0.34 ; 1.18)$ & $0.66(0.35 ; 1.24)$ \\
\hline \multicolumn{4}{|l|}{ Hypertension } \\
\hline General population & $50(43.1)$ & 1.00 (reference) & 1.00 (reference) \\
\hline Homeless & $39(33.6)$ & $0.78(0.51 ; 1.19)$ & $0.87(0.57 ; 1.33)$ \\
\hline \multicolumn{4}{|c|}{ Self-reported health status/healthcare use } \\
\hline \multicolumn{4}{|l|}{ Hypertension } \\
\hline General population & $21(18.1)$ & 1.00 (reference) & 1.00 (reference) \\
\hline Homeless & $12(10.3)$ & $0.57(0.28 ; 1.16)$ & $0.64(0.31 ; 1.31)$ \\
\hline \multicolumn{4}{|l|}{ Dyslipidemia } \\
\hline General population & $47(40.5)$ & 1.00 (reference) & 1.00 (reference) \\
\hline Homeless & $9(7.9)$ & $0.19(0.10 ; 0.40)$ & $0.21(0.10 ; 0.43)$ \\
\hline \multicolumn{4}{|l|}{ Diabetes } \\
\hline General population & $4(3.5)$ & 1.00 (reference) & 1.00 (reference) \\
\hline Homeless & $9(7.9)$ & $2.29(0.71 ; 7.43)$ & $2.52(0.77 ; 8.24)$ \\
\hline \multicolumn{4}{|c|}{ Evaluation of blood pressure (last year) } \\
\hline General population & $90(77.6)$ & 1.00 (reference) & 1.00 (reference) \\
\hline Homeless & $73(62.9)$ & $0.81(0.60 ; 1.10)$ & $0.82(0.60 ; 1.13)$ \\
\hline \multicolumn{4}{|c|}{ Blood biochemical analyses(last year) } \\
\hline General population & $73(62.9)$ & 1.00 (reference) & 1.00 (reference) \\
\hline Homeless & $87(76.3)$ & $1.21(0.89 ; 1.66)$ & $1.24(0.90 ; 1.69)$ \\
\hline
\end{tabular}

PR: prevalence ratio; $95 \% \mathrm{Cl}$ : $95 \%$ confidence interval.

* Adjusted for age (continuous) and education (continuous);

** High alcohol consumption defined according to the recommendations of the American Heart Association as a maximum

daily intake of $15 \mathrm{~g} /$ day for women and $30 \mathrm{~g} /$ day for men;

*** Body mass index $\geq 25 \mathrm{~kg} / \mathrm{m}^{2}$;

\# Abdominal obesity - waist circumference $\geq 102 \mathrm{~cm}$ (men) or $\geq 88 \mathrm{~cm}$ (women).

sample compared to the general population sample, regardless of sociodemographic differences.

To our knowledge, this is the first study that assesses the distribution of risk factors for cardiovascular disease in a sample of homeless subjects in
Portugal. Certain limitations of this study should be acknowledged, namely the impact of the sampling procedures and methods used to evaluate the participants on the internal and external validity of the findings. 
The study of the homeless presents a challenge due to difficulties in recruiting representative samples and gaining the confidence of potential participants. Apart from the fact that the homeless population is numerically small and unevenly distributed, many homeless live in anonymity and frequently practice illegal or socially sanctioned behavior and are therefore often reluctant to participate in epidemiological studies 18,29,42,43. As a result, available data is scarce in Portugal and probably underestimates the burden of homelessness 44 . To circumvent these obstacles we opted to use a venue-based sampling method, with a systematic selection of the subjects attending each setting and the recruitment following reproducible procedures that are not expected to introduce additional bias. The support institutions, such as the ones selected for our investigation, are meeting places where homeless tend to concentrate. These are "open-doors" organizations that provide food, clothes or accommodation to heterogeneous groups of individuals, including drug addicts, alcoholics, prostitutes, single persons, families and elderly people 45 , and are therefore expected to represent the heterogeneity of homelessness. The other invited institutions that did not participate are similar to the participating organizations (Associação dos Albergues Nocturnos do Porto-AANP, Serviço de Assistência Organizações de Maria SAOM, and Centro Social e Paroquial Nossa Senhora da Vitória - CSPNSV) in their objectives and services provided, and are therefore expected to target similar populations. We observed virtually no overlapping between our subsamples, probably because the AANP hostels also provide meals to their homeless residents and consequently their users are less likely to need to use meals programs services. We estimate that our sample includes at least $10.5 \%$ of the homeless living in Porto, since data provided by several organizations that provide social support estimate that the number of homeless people in the city ranges between 358 and 1,394 46 .

Our results suggest that the assessment of risk factors for cardiovascular disease, and probably other health problems, among "houseless" individuals may rely on recruitment strategies focused on either of these two types of institutions. However, studies including "roofless" individuals are important for a broader understanding of the association between different homeless settings and the distribution of risk factors for cardiovascular disease.

We evaluated only the homeless subjects that are classified as "houseless" according to the FEANTSA definition. Therefore, our conclusions only apply to this subset of the homeless population in Porto. Moreover, the comparison between the homeless and the general population only applies to Portuguese subjects, since the EPIPorto sample did not include people of other nationalities.

We were unable to match all the homeless with subjects from the general population because some of the homeless were young individuals with very low education levels whose characteristics correspond to a very small proportion of the non-homeless population. However this does not negatively affect the internal validity of the comparisons. Furthermore, although most participants were matched based on relatively strict criteria, adjusted estimates were also calculated to control residual confounding, thus strengthening the validity of our findings.

Since this was a cross sectional study, the causal relation between homelessness and some risk factors for cardiovascular disease cannot be firmly established. It is likely that a large proportion of individuals practiced addictive behaviors such as alcohol and tobacco consumption 12 before they became homeless. Therefore, although the associations observed in the present study depict the burden of risk factors for cardiovascular disease among the homeless in comparison with the general population, the differences are not necessarily a consequence of homelessness.

In comparison with samples of homeless people described in other countries, our sample shows a similar distribution for most sociodemographic and homelessness characteristics 14,47,48. The low proportion of women and low education level in both homeless samples is in accordance with previous observations 14,49 . The proportion of non-Portuguese individuals among the homeless was higher than in the general population $(12.3 \%$ vs. $5 \%$ ) 50 , which can be explained by the immigration of a large number of citizens from Portuguese ex-colonies and eastern European countries, most of which currently have difficulties finding employment and do not have any social or family relations in Portugal which in turn makes them more vulnerable to homelessness. The high percentage of individuals that had been imprisoned or that used illicit drugs is also consistent with previous studies that reported prevalence of drug abuse ranging between $20 \%$ and $84.4 \% 49,51,52$ and of imprisonment ranging between $23.1 \%$ and $76 \%$ 48,52. Approximately ten percent of the homeless participants reported having HIV/AIDS, in agreement with previous studies 53,54 .

Despite homeless individuals having been reported as a heterogeneous group, our results show little difference between the homeless selected from homeless hostels and those from institutions providing meals programs. This shows that monitoring exposure to risk factors for cardiovascular 
disease among this population may rely on samples recruited either in homeless hostels or institutions providing meals programs. However, more pronounced differences are expected between "houseless" and "roofless" individuals 55 .

The association between homelessness and smoking and a tendency for higher alcohol intake among homeless drinkers is in accordance with previous studies that reported a higher prevalence of smoking and alcohol abuse among homeless populations 13,14 .

A lower average body mass index and waist circumference compared to the general population sample is in accordance with the previous reports of poor nutritional status among the homeless 49,56 . Higher prevalence of hypertension and higher average blood pressure values observed in the general population are essentially due to the high proportion of overweight and obese individuals 57 . Previous studies conducted among the homeless yielded prevalence of hypertension ranging between the $14 \%$ and $51 \%$ 14,15,17,18,19,20,21.

Contrasting with previous investigations that reported numerous barriers to the use of healthcare services by the homeless $23,24,25$, in our study no meaningful differences were found between the homeless sample and general population sample regarding recent measurement of blood pressure and blood analysis. This could be explained by the fact that the Portuguese Constitution establishes that all citizens are entitled to health protection and access to healthcare provided by the National Health Service 27. These results show that the homeless are users of public healthcare services and that their contact with the system could improve if the health professionals were aware of the specific problems regarding the health of this population and their social needs.

Our results highlighted high levels of alcohol and tobacco consumption among the homeless. Interventions to improve the health of homeless individuals should target these issues, such as smoking cessation programs or programs for the treatment of alcohol abuse. These results should contribute to the understanding of the complexity of the homelessness phenomenon and to improving actions developed by the institutions that provide social services as well as other types of social responses to this problem. Prevention and control interventions are essential to minimize the physical and social consequences of homelessness and our findings should also contribute to influencing public health policies directed at reducing inequalities and the gradual social inclusion of homeless individuals.

\section{Resumo}

Este estudo descreve a distribuição de fatores de risco cardiovascular em pessoas sem-abrigo que vivem no Porto, Portugal, recrutadas em diferentes contextos, comparando-as entre si e com a população em geral. Todos os indivíduos "sem-casa" presentes em dois albergues de sem-abrigo ou dois refeitórios sociais em dias selecionados para as avaliações foram convidados, $e$ emparelhados com indivíduos da população geral. Foram estimadas as razões de proporções ou diferenças entre médias, ajustadas para sexo, idade e educação. Nos refeitórios sociais, observou-se maior prevalência de consumo de drogas ilícitas e de história prévia de prisão no último ano, e menor pressão arterial sistólica e diastólica do que nos albergues de sem-abrigo. Os sem-abrigo apresentaram uma prevalência quase 50\% maior de fumadores, menor índice de massa corporal e perímetro da cintura, e uma probabilidade 5 vezes menor de referir dislipidemia. Este trabalho contribui para a definição de prioridades de intervenção para a redução de desigualdades sociais nessas populações com extremas carências socioeconômicas.

Sem-Teto; Hipertensão; Sobrepeso; Obesidade 


\section{Contributors}

L. P. Oliveira, M. L. Pereira, A. Azevedo and L. Lunet participated in study conception and design, acquisition, analysis and interpretation of data, drafting this article and revising it critically for important intellectual content and in the final approval of the final version for publication.

\section{Conflicts of interest}

None declared.

\section{References}

1. Hwang SW, Bugeja AL. Barriers to appropriate diabetes management among homeless people in Toronto. CMAJ 2000; 163:161-5.

2. Edgar B, Meert H. Fourth review of statistics on homelessness in Europe - 2005. Brussels: European Federation of Organizations Working with the People who are Homeless; 2005.

3. Susser E, Moore R, Link B. Risk factors for homelessness. Epidemiol Rev 1993; 15:546-56.

4. Hwang SW. Homelessness and health. CMAJ 2001; 164:229-33.

5. Kleinman M, Matznetter W, Stephens M. European integration and housing policy. London: Routledge; 1998.

6. Garibaldi B, Conde-Martel A, O'Toole T. Self-reported comorbidities, perceived needs, and sources for usual care for older and younger homeless adults. J Gen Intern Med 2005; 20:726-30.
7. Schanzer B, Dominguez B, Shrout PE, Caton CL. Homelessness, health status, and health care use. Am J Public Health 2007; 97:464-9.

8. Minnery J. Approaches to homelessness policy in Europe, the United States, and Australia. J Soc Issues 2007; 63:641-55.

9. Morrison DS. Homelessness as an independent risk factor for mortality: results from a retrospective cohort study. Int J Epidemiol 2009; 38:877-83.

10. Beijer U, Andréasson S. Physical diseases among homeless people: gender differences and comparisons with the general population. Scand J Public Health 2009; 37:93-100.

11. Hwang SW, Wilkins R, Tjepkema M, O'Campo PJ, Dunn JR. Mortality among residents of shelters, rooming houses, and hotels in Canada: 11 year follow-up study. BMJ 2009; 339:b4036. 
12. Jones CA, Perera A, Chow M, Ho I, Nguyen J, Davachi S. Cardiovascular disease risk among the poor and homeless - what we know so far. Curr Cardiol Rev 2009; 5:69-77.

13. Szerlip MI, Szerlip HM. Identification of cardiovascular risk factors in homeless adults. Am J Med Sci 2002; 324:243-6.

14. Lee TC, Hanlon JG, Ben-David J, Booth GL, Cantor WJ, Connelly PW, et al. Risk factors for cardiovascular disease in homeless adults. Circulation 2005; 111:2629-35.

15. Kaldmäe M, Zilmer M, Viigimaa M, Zemtsovskaja G, Tomberg K, Kaart T, et al. Cardiovascular disease risk factors in homeless people. Ups J Med Sci 2011; 116:200-7.

16. Fazel S, Khosla V, Doll H, Geddes J. The prevalence of mental disorders among the homeless in western countries: systematic review and meta-regression analysis. PLoS Med 2008; 5:e225.

17. Kim DH, Daskalakis C, Plumb JD, Adams S, Brawer $\mathrm{R}$, Orr N, et al. Modifiable cardiovascular risk factors among individuals in low socioeconomic communities and homeless shelters. Fam Community Health 2008; 31:269-80.

18. Gelberg L, Linn LS. Assessing the physical health of homeless adults. JAMA 1989; 262:1973-9.

19. Takano T, Nakamura K, Takeuchi S, Watanabe M. Disease patterns of the homeless in Tokyo. J Urban Health 1999; 76:73-84.

20. Gelberg L, Andersen RM, Leake BD. The behavioral model for vulnerable populations: application to medical care use and outcomes for homeless people. Health Serv Res 2000; 34:1273-302.

21. Folsom DP, McCahill M, Bartels SJ, Lindamer LA, Ganiats TG, Jeste DV. Medical comorbidity and receipt of medical care by older homeless people with schizophrenia or depression. Psychiatr Serv 2002; 53:1456-60.

22. Kubisova D, Adamkova V, Lanska V, Dlouhy P, Rambouskova J, Andel M. Higher prevalence of smoking and lower BMI, waist circumference, cholesterol and triacylglyceride levels in Prague's homeless compared to a majority of the Czech population. BMC Public Health 2007; 7:51.

23. Kidder DP, Wolitski RJ, Campsmith ML, Nakamura GV. Health status, health care use, medication use, and medication adherence among homeless and housed people living with HIV/AIDS. Am J Public Health 2007; 97:2238-45.

24. Kushel MB, Vittinghoff E, Haas JS. Factors associated with the health care utilization of homeless persons. JAMA 2001; 285:200-6.

25. O’Toole TP, Gibbon JL, Hanusa BH, Fine MJ. Utilization of health care services among subgroups of urban homeless and housed poor. J Health Polit Policy Law 1999; 24:91-114.

26. Whitney N, Glazier R. Factors affecting medication adherence among the homeless: a qualitative study of patients' perspective. Univ Toronto Med J 2004; 82:6-9.

27. Pita Barros P, Simões J. Health systems in transition: Portugal health system review. Copenhagen: The European Observatory on Health Systems and Policies; 2007.
28. Edgar B, Meert H. European review of statistics on homelessness - 2009. Brussels: European Federation of Organizations Working with the People who are Homeless; 2009.

29. Magnani R, Sabin K, Saidel T, Heckathorn D. Review of sampling hard-to-reach and hidden populations for HIV surveillance. AIDS 2005; 19 Suppl 2:S67-72.

30. Khadduri J, Culhane D. The 2009 annual homeless assessment report. Washington DC: U.S. Department of Housing and Urban Development; 2010.

31. Robinson WT, Risser JMH, McGoy S, Becker AB, Rehman H, Jefferson M, et al. Recruiting injection drug users: a three-site comparison of results and experiences with respondent-driven and targeted sampling procedures. J Urban Health 2006; 83Suppl 1:29-38.

32. Muhib FB, Lin LS, Stueve A, Miller RL, Ford WL, Johnson WD, et al. A venue-based method for sampling hard-to-reach populations. Public Health Rep 2001; 116 Suppl 1:216-22.

33. Perloff D, Grim C, Flack J, Frohlich ED, Hill M, McDonald M, et al. Human blood pressure determination by sphygmomanometry. Circulation 1993; 88(5 Pt 1):2460-70.

34. Santos AC, Barros H. Prevalence and determinants of obesity in an urban sample of Portuguese adults. Public Health 2003; 117:430-7.

35. Ramos E, Lopes C, Barros H. Investigating the effect of nonparticipation using a population-based casecontrol study on myocardial infarction. Ann Epidemiol 2004; 14:437-41.

36. Chobanian AV, Bakris GL, Black HR, Cushman WC, Green LA, Izzo Jr. JL, et al. Seventh report of the Joint National Committee on Prevention, Detection, Evaluation, and Treatment of High Blood Pressure. Hypertension 2003; 42:1206-52.

37. Clinical guidelines on the identification, evaluation, and treatment of overweight and obesity in adults: executive summary. Expert Panel on the Identification, Evaluation, and Treatment of Overweight in Adults. Am J Clin Nutr 1998; 68:899-917.

38. Expert Panel on Detection Evaluation, and Treatment of High Blood Cholesterol in Adults. Executive Summary of The Third Report of The National Cholesterol Education Program (NCEP) Expert Panel on Detection, Evaluation, And Treatment of High Blood Cholesterol In Adults (Adult Treatment Panel III). JAMA 2001; 285:2486-97.

39. Lopes C, Oliveira A, Santos AC, Ramos E, Gaio AR, Severo M, et al. Consumo alimentar no Porto. Porto: University of Porto Medical School; 2006.

40. Krauss RM, Eckel RH, Howard B, Appel LJ, Daniels SR, Deckelbaum RJ. AHA dietary guidelines: revision 2000. A statement for healthcare professionals from the Nutrition Committee of the American Heart Association. Circulation 2000; 102:2284-99.

41. McNutt LA, Wu C, Xue X, Hafner JP. Estimating the relative risk in cohort studies and clinical trials of common outcomes. Am J Epidemiol 2003; 157:940-3.

42. Thompson SK, Collins LM. Adaptive sampling in research on risk-related behaviors. Drug Alcohol Depend 2002; 68 Suppl 1:S57-67. 
43. Heckathorn DD, Salaam S, Broadhead RS, Hughes JJ. Extensions of respondent-driven sampling: a new approach to the study of injection drug users aged 18-25. AIDS Behav 2002; 13:55-67.

44. Barreto E, Bento A. Sem-amor sem-abrigo. Lisboa: Climepsi Editores; 2002.

45. Cruz S, Neves M, Quintas R, Quintas A, Bastos V. Vidas à parte: passado, presente e futuro. Porto: Associação dos Albergues Nocturnos do Porto; 2006.

46. Instituto da Segurança Social. Estudo dos sem-abrigo. Lisboa: Instituto da Segurança Social; 2005.

47. Larimer ME, Malone DK, Garner MD, Atkins DC, Burlingham B, Lonczak HS, et al. Health care and public service use and costs before and after provision of housing for chronically homeless persons with severe alcohol problems. JAMA 2009; 301: 1349-57.

48. Levitt AJ, Culhane DP, DeGenova J, O'Quinn P, Bainbridge J. Health and social characteristics of homeless adults in Manhattan who were chronically or not chronically unsheltered. Psychiatr Serv 2009; 60:978-81.

49. Langnäse K, Müller MJ. Nutrition and health in an adult urban homeless population in Germany. Public Health Nutr 2001; 4:805-11.

50. Presidência da República Portuguesa. Diagnóstico - os números possíveis da imigração em Portugal. http://www.presidencia.pt/?idc=24\&idi=1743 (accessed on Oct/2011).

51. Grinman MN, Chiu S, Redelmeier DA, Levinson W, Kiss A, Tolomiczenko G, et al. Drug problems among homeless individuals in Toronto, Canada: prevalence, drugs of choice, and relation to health status. BMC Public Health 2010; 10:94.
52. Kushel MB, Hahn JA, Evans JL, Bangsberg DR, Moss AR. Revolving doors: imprisonment among the homeless and marginally housed population. Am J Public Health 2005; 95:1747-52.

53. Culhane DP, Gollub E, Kuhn R, Shpaner M. The co-occurrence of AIDS and homelessness: results from the integration of administrative databases for AIDS surveillance and public shelter utilisation in Philadelphia. J Epidemiol Community Health 2001; 55:515-20.

54. Estebanez PE, Russell NK, Aguilar MD, Béland F, Zunzunegui MV. Women, drugs and HIV/AIDS: results of a multicentre European study. Int J Epidemiol 2000; 29:734-43.

55. Nyamathi AM, Leake B, Gelberg L. Sheltered versus nonsheltered homeless women differences in health, behavior, victimization, and utilization of care. J Gen Intern Med 2000; 15:565-72.

56. Luder E, Ceysens-Okada E, Koren-Roth A, MartinezWeber C. Health and nutrition survey in a group of urban homeless adults. J Am Diet Assoc 1990; 90:1387-92.

57. Camões M, Lopes C, Oliveira A, Santos AC, Barros H. Overall and central obesity incidence in an urban Portuguese population. Prev Med 2010; 50:50-5.

Submitted on 29/Nov/2011

Final version resubmitted on 01/Mar/2012 Approved on 27/Mar/2012 